\title{
ECHO OF LODHRADI KASHAYA IN LIPID PROFILE OF TYPE 2 DIABETES MELLITUS PATIENTS
}

\author{
VARUN KUMAR SINGH, KRC REDDY*
}

Department of Rasa Shastra, Institute of Medical Sciences, Banaras Hindu University, Varanasi, Uttar Pradesh, India. Email: drkrcreddybhu@yahoo.co.in

Received: 24 November 2016, Received and Accepted: 27 February 2017

ABSTRACT

Objective: Lipid profile is matter to concern in fast changing lifestyle, and especially in diabetic mellitus (DM) patients. In arena of DM, obesity and high lipid contour is a causative problem and lead to generate the related problems too. Hence, tracking of lipid profile in DM patients is necessary as part of treatment approach. Hence, the present study was conducted to track the effect of Lodhradi Kashaya spray dried (LKSD) powder on lipid profile in Type $2 \mathrm{DM}$ patients.

Methods: Total 31 patients were taken following the guideline mention in Central Council for Research in Ayurveda and Siddha protocol for DM research. They were divided into two groups, Groups A and B and given LKSD ( 4 and $2 \mathrm{~g}$ TDS (three times a day), respectively, dissolved in water) for 3 months. They are investigated for their blood serum creatinine and lipid profile (cholesterol, low-density lipoprotein [LDL], high-density lipoprotein [HDL], very LDL [VLDL], and triglyceride). The patients response has also been noted regarding palatability acceptance and ease of administration.

Result: LKSD was found significantly effective in total cholesterol ( $p=0.001$ and 0.073 ), triglyceride ( $p=0.002$ and 0.003 ), HDL ( $<<0.001$ and 0.026 ), LDL ( $\mathrm{p}=0.563$ and $\mathrm{p}<0.001)$, and VLDL ( $\mathrm{p}=0.024$ and 0.003$)$. Patients had reported that formulation is easy to take in spite of its astringency in taste.

Conclusion: Lodhradi Kashaya has capability to control and take care of disturbance in lipid profile in DM patients and thus enhance their living confidence.

Keywords: Ayurveda, Lodhradi Kashaya, Diabetes mellitus, Clinical study, Lipid profile.

(C) 2017 The Authors. Published by Innovare Academic Sciences Pvt Ltd. This is an open access article under the CC BY license (http://creativecommons. org/licenses/by/4. 0/) DOI: http://dx.doi.org/10.22159/ajpcr.2017.v10i5.16326

\section{INTRODUCTION}

Lipid profile is considered as outcome of disturbed metabolism and improper lifestyle. It is also causative factor for many of ailments and complications in the body as well as it also being worst in a progressive manner in case of metabolism related disease like diabetes mellitus (DM). Diabetes is characterized by chronic hyperglycemia and disturbances of carbohydrate, lipid and protein metabolism. On the other hand, obesity is important preventable cause of death global, with increasing prevalence in adults and children, and authorities view it as one of the most serious public health diseases of the $21^{\text {st }}$ century. According to the WHO global estimates, about $13 \%$ of the world's adult population (11\% of men and $15 \%$ of women) was obese in 2014 [1]. A positive association between obesity and the risk of developing noninsulindependent diabetes mellitus (NIDDM) has been repeatedly observed in both cross-sectional [2] and prospective studies [3]. The consistency of the association across populations despite difference measures of fatness and criteria for diagnosing NIDDM reflects the strength of the relationship, i.e., the risk of NIDDM increases continuously with body mass index (BMI) and decreases with weigh loss [4]

It has been established that DM patients have more prone to develop hyperlipidemia. Their physiology responded to decrease high-density lipoprotein (HDL), increase low-density lipoprotein (LDL), very LDL (VLDL), and triglyceride. Hyperlipidemia predisposes premature atherosclerosis and macrovascular complication too [5].

Insulin resistance and Type 2 diabetes are associated with a clustering of interrelated plasma lipid and lipoprotein abnormalities, which include reduced HDL-cholesterol (HDL-C), a predominance of small dense LDL particles, and elevated triglyceride levels. In fact, prediabetic individuals often exhibit an atherogenic pattern of risk factors that includes higher levels of total cholesterol, LDL cholesterol, and triglycerides, and lower levels of HDL-C than individuals who do not develop diabetes [6]. The prevalence of dyslipidemia in DM patients is $95 \%$. It is also a major risk factor for coronary heart disease (CHD). Cardiovascular disease is a cause of morbidity and mortality in patients with DM because of disturbance in lipoproteins, i.e., serum triglycerides $69 \%$, serum cholesterol 56.6\%, LDL 77\%, and HDL 71\% [7,8]. Hence, tracking of lipid profiles along with blood sugar level is becoming more important parameter in treatment approach. Hence, an ayurvedic formulation has been taken for study its role in DM as it was said "Madhumehajeet" in Basavarajiyam. The same formulation also has been dictated in Charak Samhita and Vaidya Chintamani under Prameha Prakaranam. In present clinical assessment, our main focus to see pattern of lipid profile during treatment with Lodhradi Kashaya spray dried (LKSD). Ingredients of LKSD (Table 1) have also separately reported for hypolipidemic action or for reducing obesity in contemporary research, and thus we analyzed here about their role in controlling lipid profile in Type 2 DM patients.

\section{METHODS}

\section{Study design}

Total 36 patients were registered for a clinical trial at outpatient department, Indian Medicine Wing, Sir Sunderlal Hospital, Banaras Hindu University, Varanasi in which 5 patients were dropped out. Inclusion criteria for selection of diabetic patients of either sex, age group of 30-70 years, $8 \mathrm{hrs}$ fasting blood sugar (FBS) $>126$ and $<250 \mathrm{mg} / \mathrm{dl}$ and $2 \mathrm{hrs}$ postprandial blood sugar $>200$ to $<350 \mathrm{mg} / \mathrm{dl}$. We had excluded the patients not lying in the parameter of inclusion criteria and patients suffering from retinopathy, nephropathy, cardiovascular problems, hormonal imbalance, regnant, and lactating mother. Their lipid profile has been investigated at starting and end of the study (3 months duration). We have followed the protocol of Central Council for Research in Ayurveda and Siddha for DM [9] with little modification. This clinical study has been registered in Institutional 
Table 1: Ingredients of Lodhradi Kashaya

\begin{tabular}{lllll}
\hline Serial & Plant & Botanical name & Family & Ratio \\
\hline 1 & Lodhra & Symplocos racemosa Roxb. & Symplocaceae & Stem bark \\
2 & Haritaki & Terminalia chebula Retz. & Combretaceae & Fruit pulp \\
3 & Musta & Cyperus rotundus Linn. & Cyperaceae & Rhizome \\
4 & Katphala & Myrica nagi Linn. & Myricaceae & Stem bark \\
\hline
\end{tabular}

Ethical Committee, Institute of Medical Sciences, Banaras Hindu University as "ECR/526/Inst./UP/2014."

\section{Trial drugs}

For this study, Lodhradi Kashaya has been made available to patients as LKSD powder. For this purpose, we have modified the Kashaya (decoction) form into powder dosage form, using spray drier technology at Sanat Products Ltd., Sikandrabad, Noida, Uttar Pradesh [10]. To maintain its quality and reproducibility, LKSD was standardized on several parameters [11]. To ensure the administration of LKSD as Kashaya, it was strictly recommended to dissolve unit dose it into lukewarm water to make Kashaya like form.

\section{Patients grouping}

Total 31 patients were divided into two group, Groups A and B having 14 patients and 17 patients, respectively. Group A (patients having FBS more than 160) was given a dose of $4 \mathrm{~g}$ total dissolved solids (TDS) while Group B (patients having FBS <160) was given 2 g TDS of Lodhradi Kashaya powder. The patients were strictly advised to dissolve unit dose of powder into $100 \mathrm{ml}$ lukewarm water just before administration and drink it. Patients are advised to do regular exercise and diet control as prescribed to avoid high sugar and fat content diet. Patients are also advised to examine lipid profile and council to take Lodhradi Kashaya in proper manner.

\section{Statistical analysis}

Findings were analyzed statistically by SPSS 16.00 version applying the paired t-test, one-way ANOVA, Friedman test, and Chi-square test. The results are interpreted with possible co-relation of ayurvedic and contemporary point of view. $\mathrm{p}<0.05$ was considered statistically significant and $\mathrm{p}<0.001$ was considered highly significant in the results of this study.

\section{RESULT}

All the patients were selected independently of their sex, age, caste, economy, and religions. Total 36 patients were registered while 5 have left the study due to their own consent. The patients variable and their profile were given in Table 2. In this patient distribution, it was seen that male patients are more in number with age group of 40-70 years. In patients, it was observed that most of the patients do not have a diabetic history in family and BMI more than 25 had showed strong presence in distribution. In this study, when we analyzed the lipid profile of the patients, LKSD was found significantly effective in total cholesterol $(\mathrm{p}=0.001$ and 0.073$)$, triglyceride $(\mathrm{p}=0.002$ and 0.003$)$, HDL $(\mathrm{p}<0.001$ and 0.026$)$, LDL ( $p=0.563$ and $<0.001)$, and VLDL ( $p=0.024$ and 0.003 ) for Groups A and B, respectively (Tables 3 and 4). Patients had reported that formulation is easy to take in spite of its astringency in taste.

\section{DISCUSSION}

Peoples around the world are bending toward herbal medicines as they suppose it biological and medicinal activities, higher safety margins, consumer own interest and reasonable cost for long-term use, and to avoid long-term adverse drug reactions. In the market, consumers are looking for natural ingredients in food, drugs and cosmetics as they believe that anything natural will be more safe and devoid of side effects [12]. Ayurveda also have upper hand in service of humanity with ingredients from natural resources as well as recognition of prediabetes stage described in ayurvedic science such as knotted hair, burning sensation, numbness, sweetness in mouth, laziness, body odor like fish
Table 2: Patients distribution and variables

\begin{tabular}{llll}
\hline Patients variables & $\begin{array}{l}\text { Division of } \\
\text { variables }\end{array}$ & $\begin{array}{l}\text { Group A } \\
\text { percentage } \\
\text { of patients }\end{array}$ & $\begin{array}{l}\text { Group B } \\
\text { percentage } \\
\text { of patients }\end{array}$ \\
\hline Number of patients & Total & 14 & 17 \\
Age group (years) & $30-40$ & 7.10 & 17.64 \\
& $41-50$ & 28.57 & 29.41 \\
& $51-60$ & 35.71 & 29.41 \\
Sex & $61-70$ & 28.57 & 23.52 \\
Diabetic family & Male & 100 & 82.2 \\
history & Female & 0 & 11.8 \\
& Yes & 28.10 & 17.6 \\
Diet & & & \\
& No & 71.6 & 82.4 \\
Addiction & Vegetarian & 57.1 & 29.4 \\
& Mixed & 42.9 & 70.6 \\
BMI & Tobacco & 35.7 & 11.8 \\
& Smoking & 14.3 & 0 \\
& Alcohol & 7.1 & 0 \\
& $\leq 18$ & 0 & 0 \\
\hline
\end{tabular}

BMI: Body mass index

whereas modern science has no such criteria. DM is due to increase in vata caused by either blockage of strota (body channel) by aggravated kapha and medodhatu or due to mental stress, food habit, lifestyle, etc. [13] which can be co-related that high BMI and obesity in patients were reason behind DM. In low BMI patients, improper metabolism as well as malfunctionality of pancreas is also reason for DM. Here a formulation, Lodhradi Kashaya (Table 1) was selected for study having natural ingredients from arena of ayurvedic wisdom as it was dictated as 'Madhumehajeet (winner of DM)' in Basavarajeeyam and the same formulation was also mentioned in Vaidya Chintamani and Charaka Samhita too $[14,15]$. This formulation was indicated to take as Kwath form (decoction), so here we made an attempt to modify the dosage form as LKSD powder which was indicated to dissolve into lukewarm water just before administration so that we can stick to fundamental prescribed dosage form while validating the ancient wisdom. Kashaya was indicated to take in 2 pala (Sharangdhar Samhita) or 1 pala (Yadav ji Tikram Ji) in divided dose while in the Ayurvedic Pharmacopoeia of India suggest to take kashaya obtained from $48 \mathrm{~g}$ of Kwath churna. If we make Kwath and dry it, then we gat yield of about $12 \mathrm{~g}$ ( 2 pala Kwath) and $6 \mathrm{~g}$ ( 1 pala Kwath) in a day. So on this basis two doses, i.e., $4 \mathrm{~g}$ TDS and $2 \mathrm{~g}$ TDS dose has been decided for human being. Patients were grouped into A (FBS $\geq 160)$ and $B(F B S<160)$ were given treatment with $4 \mathrm{~g}$ TDS and $2 \mathrm{~g}$ TDS, respectively. So ancient wisdom always talks about management of disease not only targeting the hypoglycemic action but also on other factors such as lipid profile and liver profile.

In presented clinical study, total 31 diabetic patients were registered for the study of effect of Lodhradi Kashaya on their diabetic profile including lipid profile in them. They are divided into Groups A and B based on their diabetic intensity (Table 2), i.e., patients having FBS >160 are placed in Group B while FBS below 160 were placed in Group B. Blood sugar, hemoglobin $\mathrm{A} 1 \mathrm{C}$, and liver function test profile were improved significantly during course of treatment with LKSD [16]. Hence here, lipid profile was focused to know the variation in them. Lipid profile was assessed at starting of study ( 0 day) and end of study (90 days) by assessing five parameters, viz., total cholesterol, triglyceride, HDL, 
LDL, and VLDL. The association between lipid profile and body fat distribution has been much discussed during the past decades.

Both lipid profile and body fat mass have been shown to be the important predictors for metabolic disturbances and serious medical conditions, including dyslipidemia, hypertension, diabetes, cardiovascular diseases, among other $[17,18]$. Lipid abnormalities are common in diabetics and frequently seen in type 2 diabetics. Dyslipidemia make diabetics prone to develop CHD and other complications of atherosclerosis. This variation in lipid profile of DM patients in prevalence may be due to differences in BMI and possibly genetic variation. In diabetes many factors may affect blood lipid levels, because of interrelationship between carbohydrates and lipid metabolism. Therefore, any disorder in carbohydrate metabolism leads to disorder in lipid metabolism and vice versa [19]. In this study, LKSD significantly reduces the total cholesterol (Table 3 ) in Group A $(\mathrm{t}=4.48, \mathrm{p}=0.001)$, while in Group B decrease is not significant $(t=1.91 ; p=0.073)$. Overall in both groups total cholesterol amount was decreased; thus we can say that LKSD is effective more in case A. In higher dose of LKSD (4 g TDS), it is significantly effective in reducing cholesterol level. This may be due to that, patient criteria of grouping affect the extent of reduction. In Group A, the patients (FBS above 160) are developing more abnormalities thus producing more total cholesterol that are controlled by the higher dose in presented study. Lodhradi Kashaya also significantly reduced the level of triglyceride in both Groups A and B patients (Table 3). However, it was found more significant in Group B ( $t=3.72, p=0.002)$ in comparison of Group A $(t=3.56, p=0.003)$. HDL so called good cholesterol, acts by enhancing the removal of cholesterol from the peripheral tissues and so reduces the body's cholesterol pool. Type 2 DM was usually associated with low plasma levels of HDL, and there were also lower mean HDL concentrations in hypertensive type 2 diabetic males and hypertensive type 2 diabetic females. Low HDL-C concentrations are often accompanied by elevated triglyceride levels. The denser LDL particles acquire a large proportion of these HDL esters, further diminishing the HDL and decrease its level [20]. HDL is decreased due to an abnormality in digestion and metabolism and due to defect in metabolic reactions. HDL level was increased significantly in both groups treated with LKSD (Table 4). Increase in HDL was found highly significance Group A $(t=-5.14, p<0.001)$, while in Group B increase was found significant ( $\mathrm{t}=-2.45, \mathrm{p}=0.026)$. LDL was found to decrease nonsignificantly in Group B ( $t=0.591, p=0.563)$ and significantly in Group A ( $t=5.46, p<0.001)$. However, if it was analyzed, then it shows that LKSD decreases LDL in all the diabetic patients (Table 4). The result was found highly significant in the higher dose (4 g TDS) which indicate that it was more effective when given in higher dose with the association between elevated blood glucose concentrations and low concentrations of HDL. Hyperglycemia progressively increases the transfer of cholesterol esters from HDL to VLDL particles. LKSD was found effective in lowering the VLDL during the study in DM patients, and found significant in both Groups A and B (Table 4). Among them, LKSD was found more effective in Group B $(\mathrm{t}=2.48, \mathrm{p}=0.024)$, in comparison to Group A ( $\mathrm{t}=3.61, \mathrm{p}=0.003)$. Since, ingredients of LKSD (Table 1), i.e., Lodhra [21], Musta, Katphala, and Haritaki have well-established evidence of hypolipidemic action and hepatoprotective. These actions may be due to phytoconstituents such as tannins, polyphenols, saponins, and many other antioxidants in the formulation. Saponin modulates the expression of many genes associated with lipid metabolism and hence regulates hyperlipidemia associated with diabetes by: (a) Modulation of leptin, adiponectin, as well as the inhibition of insulin resistance (b) enhancing the expression of peroxisome proliferator-activated receptor a key transcriptional factor in adipogenesis regulation, (c) reduction of triglyceride, and (d) reduction of serum cholesterol. Phenolic compounds have been attributed to induction of $\beta$-cell regeneration and a direct action on adipose cells all these phytoconstituents are collectively responsible for overall effect of LKSD on lipid profile in DM patients [22].

\section{CONCLUSION}

When we look on scenario of diabetic patients and compare the reason behind it as well as several complications arises after it, then, we found that lipid profile is very important factor to look out and need attention. Lodhradi Kashaya was mentioned century years before in Charaka Samhita, Vaidya Chintamani and Basavarajeeyam for the management of Prameha, and Madhumeha. In the $21^{\text {st }}$ century Lodhra, Musta, Katphala, and Haritaki are widely reported for hypolipidemic action. In this study, Lodhradi Kashaya was found effective in controlling the disturbance in lipid profile of diabetic patients thus encouraging to do more work in this direction.

Table 3: Effect of LKSD on total cholesterol and triglyceride

\begin{tabular}{|c|c|c|c|c|c|c|}
\hline \multirow[t]{2}{*}{ Groups } & \multicolumn{3}{|c|}{ Total cholesterol } & \multicolumn{3}{|l|}{ Triglyceride } \\
\hline & 0 day & 90 days & $\begin{array}{l}\text { Within the group } \\
\text { Paired t-test 0-90 days }\end{array}$ & 0 day & 90 days & $\begin{array}{l}\text { Within the group } \\
\text { Paired t-test } 0-90 \text { days }\end{array}$ \\
\hline A & $184.31 \pm 28.33$ & $164.21 \pm 18.12$ & $\begin{array}{l}t=4.48 \\
p=0.001\end{array}$ & $199.68 \pm 80.21$ & $164.31 \pm 47.88$ & $\begin{array}{l}t=3.56 \\
p=0.003\end{array}$ \\
\hline B & $181.88 \pm 43.82$ & $165.60 \pm 40.17$ & $\begin{array}{l}\mathrm{t}=1.91 \\
\mathrm{p}=0.073\end{array}$ & $239.76 \pm 89.86$ & $205.59 \pm 78.85$ & $\begin{array}{l}\mathrm{t}=3.72 \\
\mathrm{p}=0.002\end{array}$ \\
\hline
\end{tabular}

LKSD: Lodhradi Kashaya spray dried

Table 4: Effect of LKSD on HDL, LDL, and VLDL

\begin{tabular}{|c|c|c|c|c|c|c|c|c|c|}
\hline \multirow[t]{3}{*}{ Group } & \multicolumn{9}{|l|}{ Mean \pm SD } \\
\hline & \multicolumn{3}{|l|}{ HDL } & \multicolumn{3}{|l|}{ LDL } & \multicolumn{3}{|l|}{ VLDL } \\
\hline & 0 day & 90 days & $\begin{array}{l}\text { Within the } \\
\text { group } \\
\text { Paired t-test }\end{array}$ & 0 day & 90 days & $\begin{array}{l}\text { Within the } \\
\text { group } \\
\text { Paired t-test }\end{array}$ & 0 day & 90 days & $\begin{array}{l}\text { Within the } \\
\text { group } \\
\text { Paired } \\
\text { t-test }\end{array}$ \\
\hline A & $36.30 \pm 5.85$ & $41.67 \pm 3.00$ & $\begin{array}{l}t=-5.14 \\
p<0.001\end{array}$ & $107.29 \pm 21.11$ & $93.08 \pm 21.97$ & $\begin{array}{l}t=5.46 \\
p<0.001\end{array}$ & $47.20 \pm 32.33$ & $45.03 \pm 30.58$ & $\begin{array}{l}t=3.61 \\
p=0.003\end{array}$ \\
\hline B & $37.82 \pm 7.33$ & $40.34 \pm 5.67$ & $\begin{array}{l}\mathrm{t}=-2.45 \\
\mathrm{p}=0.026\end{array}$ & $94.11 \pm 25.84$ & $90.88 \pm 28.10$ & $\begin{array}{l}t=0.591 \\
p=0.563\end{array}$ & $51.80 \pm 31.04$ & $47.20 \pm 28.08$ & $\begin{array}{l}\mathrm{t}=2.48 \\
\mathrm{p}=0.024\end{array}$ \\
\hline
\end{tabular}

LDL: Low-density lipoprotein, HDL: High-density lipoprotein, VLDL: Very low-density lipoprotein, LKSD: Lodhradi Kashaya spray dried 


\section{ACKNOWLEDGMENT}

We are thankful to Ministry of Science and Technology for DST-INSPIRE Fellowship award and financial support to Ph.D work. We are also thankful to Dr. Guruprasad C Nille, Junior Resident, Department of Rasa Shastra, IMS, BHU for their support in clinical study.

\section{REFERENCES}

1. WHO. Fact about obesity. Available from: http://www.who.int/ mediacentre/factsheets/fs311/en/. [Last accessed on 2016 Nov 21].

2. Leong A, Porneala B, Dupuis J, Florez JC, Meigs JB. Type 2 diabetes genetic predisposition, obesity, and all-cause mortality risk in the U.S.: A multiethnic analysis. Diabetes Care 2016;39:539-46.

3. Ahima RS. Connecting obesity, aging and diabetes. Nat Med 2009;15(9):996-7.

4. Ganz ML, Wintfeld N, Li Q, Alas V, Langer J, Hammer M. The association of body mass index with the risk of Type 2 diabetes: A casecontrol study nested in an electronic health records system in the United States. Diabetol Metab Syndr 2014;6(1):50.

5. Uttra KM, Devrajani BM, Shah SZ, Devrajani T, Das T, Raza S, et al. Lipid profile of patients with diabetes mellitus (A multidisciplinary study). World Appl Sci J 2011;12:1382-4.

6. Krauss RM. Lipids and lipoproteins in patients with Type 2 diabetes. Diabetes Care 2004;27(6):1496-504

7. Gadi R, Samaha FF. Dyslipidemia in Type 2 diabetes mellitus. Curr Diab Rep 2007;7(3):228-34.

8. Khan SR, Ayub N, Nawab S, Shamsi TS. Triglyceride profile in dyslipidaemia of Type 2 diabetes mellitus. J Coll Physicians Surg Pak 2008;18(5):270-3

9. Lavekar GS. Clinical Research Protocol for Traditional Health Sciences. New Delhi: CCRAS; 2009. p. 459-77.

10. Singh VK, Reddy KRC. Pharmaceutical processing and standardization of modified dosage form of Lodhradi Kashaya as spray dried powder.
Int J Green Pharm 2015;9:252-6.

11. Singh VK, Reddy KRC. Standardization of modified dosage form of Lodhradi Kashaya. Asian J Pharm 2016;10 2 Suppl:134-8.

12. Singh VK, Chaudhary AK. Ayurvedic natural excipients: An advance option for modern medicaments. Int J Pharm Sci Res 2016;7:1000-13.

13. Das B, Mitra A, Hazra J. Management of madhumeha (Diabetes mellitus) with evidence and intervention with ayurvedic rasaushadhies. Indian J Tradit Knowl 2011;10:624-8.

14. Neelkanth B. In: Lavekar GS, editor. Basavarajiyam. New Delhi: Central Council for Research in Ayurvedic Sciences; 2007. p. 329.

15. Vallabhacharya. In: Reddy KR, editor. Vaidya Chintamani. Varanasi: Chaukhambha Orientalia Publication; 2013. p. 779-80.

16. Singh VK, Reddy KRC. Clinical appraisal of Lodhradi Kashaya on Type 2 diabetes mellitus patients. Int J Clin Trials 2017;4(1):58-64.

17. Bertoli A, Di Daniele N, Ceccobelli M, Ficara A, Girasoli C, De Lorenzo A. Lipid profile, BMI, body fat distribution, and aerobic fitness in men with metabolic syndrome. Acta Diabetol 2003;40 Suppl 1:S130-3.

18. Hu D, Hannah J, Gray RS, Jablonski KA, Henderson JA, Robbins DC, et al. Effects of obesity and body fat distribution on lipids and lipoproteins in nondiabetic American Indians: The Strong Heart Study. Obes Res 2000;8(6):411-21.

19. Ozder A. Lipid profile abnormalities seen in T2DM patients in primary healthcare in Turkey: A cross-sectional study. Lipids Health Dis 2014; $13: 183$.

20. Gordon L, Ragoobirsingh D, Morrison EY, Choo-Kang E, McGrowder D, Martorell E. Lipid profile of Type 2 diabetic and hypertensive patients in the Jamaican population. J Lab Physicians 2010;2(1):25-30

21. Singh VK, Reddy KRC. Management of diabetes mellitus and its complications by Lodhra: A review. Int J Ayurvedic Med 2015;6:305-9.

22. Singh VK, Reddy KRC. Review on Lodhradi Kashaya:All-rounder remedy for diabetes mellitus patients. Indian J Tradit Knowl 2017;16(1):100-6. 